\title{
Palliation of dyspnoea in advanced COPD: revisiting a role for opioids
}

\author{
G Rocker, ${ }^{1,2}$ R Horton, ${ }^{2}$ D Currow, ${ }^{3}$ D Goodridge, ${ }^{4}$ J Young, ${ }^{5}$ S Booth ${ }^{6}$
}

${ }^{1}$ Division of Respirology, OEIl Health Science Centre and Dalhousie University, Halifax Nova Scotia, Canada; ${ }^{2}$ Division of Palliative Medicine, OEII Health Science Centre and Dalhousie University, Halifax Nova Scotia, Canada; ${ }^{3}$ Flinders Centre for Clinical Change, Flinders University, Australia; ${ }^{4}$ College of Nursing, University of Saskatchewan, Saskatoon, Saskatchewan, Canada; ${ }^{5} \mathrm{New}$ Brunswick Extra Mural Program, 73 Milltown Blvd, Suite 100, St Stephen, New Brunswick, Canada; ${ }^{6}$ Addenbrookes NHS Trust, Cambridge, UK

Correspondence to: Dr G M Rocker, \#4457 Halifax Infirmary, 1796 Summer St,

Halifax, Nova Scotia, Canada B3H 3A7; gmrocker@dal.ca

Received 17 March 2009 Accepted 9 July 2009

\section{ABSTRACT}

Chronic obstructive pulmonary disease (COPD) will be the third leading cause of death worldwide by 2020 . The burdens of this increasingly prevalent illness borne by patients, their family caregivers and the healthcare system are substantial. Dyspnoea as the predominant symptom becomes increasingly difficult to palliate as COPD progresses through advanced stages and, for $50 \%$ of patients, can become refractory to conventional treatment. This narrative review focuses on the potential role for carefully initiated and titrated opioids in the management of dyspnoea for patients with advanced COPD who are not yet in a terminal stage, yet struggle with symptoms that reflect underlying mechanisms of dyspnoea that lend themselves to this approach. The many barriers that currently exist to the provision of opioids in this setting are addressed, and recommendations are provided for an approach that should engender confidence among patients, their caregivers and the physicians who treat them.

Chronic obstructive pulmonary disease (COPD) will be the third leading cause of death worldwide by $2020 .{ }^{1}$ In recent years there has been a welcome increase in the focus on the care of advanced COPD in the pages of both specialist palliative care journals ${ }^{23}$ and in the respiratory literature. ${ }^{46}$ This long overdue change reflects the reality that COPD is unique among the major diseases in western society in that its prevalence, morbidity and attributable mortality continue to rise, ${ }^{7}$ that for patients who have advanced COPD the symptom burden is substantial, ${ }^{89}$ that dyspnoea as the predominant symptom is often poorly controlled and ultimately incapacitating, ${ }^{10}$ and that palliative care services in hospital or at home and high quality symptom-focused interventional strategies in our current models of care are less accessible than they are for people with cancer. ${ }^{49}$ While palliative care in general is responding to calls to extend traditional boundaries to encompass patients with advanced non-malignant medical illness, we need innovative and effective approaches to symptom control in advanced stages of $\mathrm{COPD}^{2}$ if we are to lessen the increasing burdens that advanced COPD places on the lives of patients and caregivers alike. ${ }^{11}$

The purpose of this narrative review is to (re)consider the role of opioids in the management of the patient who lives with advanced COPD and struggles with dyspnoea refractory to conventional treatment. We also set out to describe barriers to the provision of opioid therapy.

The information for this narrative review was compiled from previous researches of MEDLINE,
CINAHL and EMBASE since 31 December 2006 and a recent review through PUBMED to February 2009. Dyspnoea has been a research interest for the last 15 years for the senior authors, and articles from personal archives, the unpublished literature, work in progress from colleagues, text books, the searching of recent journals and references from papers have also been incorporated. Where possible, original studies are cited but, to limit references to those cited, recent reviews (including several systematic reviews) have been included. Specific details of the search are available on request from the corresponding author.

\section{DYSPNOEA: THE PREDOMINANT SYMPTOM IN COPD}

Dyspnoea is the subjective experience-usually unpleasant - of discomfort with breathing. As a symptom, dyspnoea pervades all aspects of patients' lives, variously described by patients who have COPD as hard work, exhausting, painful, a constant struggle or a continuous fight. For those who live with advancing COPD, dyspnoea is a significant source of disability and profoundly affects quality of life to the extent that patients become isolated and describe themselves as existing rather than living. Dyspnoea is the symptom least well palliated by traditional approaches $^{10}$ and, despite a range of potential approaches, only $50 \%$ of patients with advanced COPD benefit from some degree of palliation ${ }^{10}$ and many live (and die) with incapacitating breathlessness. Not surprisingly, perhaps, relief of symptoms (eg, dyspnoea) was a top priority for improvements in care identified by 118 hospitalised patients with COPD in a recent Canadian multicentre study. ${ }^{12}$

\section{MECHANISIMS OF DYSPNOEA: THE BASIS FOR CONVENTIONAL AND INNOVATIVE APPROACHES}

The current knowledge of mechanisms of dyspnoea in COPD has been summarised recently in a position paper of the American Thoracic Society. ${ }^{13}$ Dyspnoea is the result of a complex interaction of signals arising from the central nervous system, upper airways, lungs and chest wall. These signals are relayed to higher brain centres where they are processed and influenced by behavioural, cognitive, contextual and environmental factors prior to the shaping of the final symptom of dyspnoea. Each individual perceives, interprets and reacts to the symptom of dyspnoea from within her/his own framework of history, experience, values and beliefs, a dynamic that can result in a broad range of symptoms affecting physical, emotional, social and/or spiritual/existential domains. Just as these 
domains contribute to the conceptual framework of "total pain", it has been proposed that they are at play in the experience of "total dyspnoea" and are likely to have a profound impact on the individual's experience of dyspnoea and their response to various treatments. ${ }^{3}$ Within the emotional domain and using advanced neural imaging, we are beginning to understand the extent of limbic and paralimbic activity in dyspnoea ${ }^{14}$ that supports approaches for people with advanced COPD that consider, in addition to conventional treatment of airflow obstruction and hyperinflation, ameliorating the significant contribution of anxiety, fears and other emotions. Altering the "central perception" of dyspnoea may be accomplished by psychosocial and pharmacological treatments.

\section{Conventional interventions: inhaled therapy}

Traditional healthcare approaches to COPD, based on the biomedical model, have been focused on the underlying pathophysiology of disease and on treating bronchoconstriction and reducing hyperinflation and airway inflammation (a longacting anticholinergic agent in addition to a combination of an inhaled long-acting $\beta$ agonist and an inhaled corticosteroid). While helpful, these therapies delivered by a variety of inhaler devices are limited in what they can achieve. As COPD progresses, other therapies beyond the conventional pharmacological approach are needed improve health-related quality of life.

\section{Adjunctive approaches: pulmonary rehabilitation and oxygen therapy}

Exercise training in the setting of a formal pulmonary rehabilitation programme improves symptom control (dyspnoea, fatigue), exercise tolerance and health-related quality of life, ${ }^{15}$ although these programmes are variably available-for example, to only $2 \%$ of patients with COPD in Canada. Homebased rehabilitation programmes are also effective. ${ }^{16}$ By the time people with COPD are experiencing severe impairment from their breathlessness, their lives will already have changed irrevocably with significant limitations to their "life space". Long-term oxygen therapy (LTOT) is often prescribed in the later stages of disease to improve survival for those people with COPD who are significantly hypoxaemic. However, LTOT can have a major impact on patients' lives by changing routines, interfering with desires to be seen as healthy, by the technical focus on machines and oxygen readings, and the restrictions oxygen therapy imposes, necessitating new rhythms in life. For others it can be seen as a way to survive, endure and adapt. Thus, LTOT may improve health-related quality of life by lessening anxiety and depression, and enhance emotional function and mastery ${ }^{17}$ but, for some, LTOT is unacceptably limiting and intolerable. ${ }^{17}$ For caregivers, the means of responding to perceived breathlessness is also important. ${ }^{18}$ However, the effectiveness of LTOT in palliating dyspnoea remains uncertain. $^{19}$

In summary, COPD should be considered beyond solely being a disease. Even when seen as an illness, there is a need within the broader context of the human experience to address both symptoms and suffering more effectively. ${ }^{20}$

\section{Innovative approaches to dyspnoea: the dyspnoea ladder}

Most clinicians are familiar with the World Health Organization analgesic ladder in the management of cancer pain. In a recent review article we proposed that a "dyspnoea ladder" should be incorporated into routine assessment and treatment of patients with progressing COPD (fig 1). ${ }^{2}$ The first step of the ladder incorporates conventional approaches to dyspnoea in COPD management. Inherent is the assumption that conventional pharmacological approaches follow recommendations of national professional societies. These approaches, if they fail to provide tolerable dyspnoea, can be supplemented by non-pharmacological approaches in step 2 (recently subjected to a Cochrane review) ${ }^{21}$ These approaches include selfmanagement education exercise training, cognitive therapy, body positioning and support for carers and education that should be optimised first. The placement of opioids on step 3 underscores the role that they might have when dyspnoea persists at an intolerable level despite optimal conventional and use of non-pharmacological approaches.

\section{Opioids, dyspnoea and COPD}

There are several mechanisms by which opioids (both endogenous and exogenous) could influence dyspnoea. Endogenous opioids might modulate dyspnoea by a reduction in total ventilation, an increase in ventilatory efficiency with exercise; a reduction in responses to hypoxia and hypercapnia; a reduction in the drive to breathe and an effect on bronchoconstriction. ${ }^{22}$ Exercise performance-related dyspnoea in COPD was recognised many years ago to be improved by exogenous opioids. ${ }^{23}$

Experience with opioid use in advanced COPD is limited, even though it has been almost 20 years since morphine was first reported to be associated with a reduction in dyspnoea symptoms in COPD. ${ }^{24}$ However, use of opioids over the long term (weeks and months or beyond) has received little attention or support, and the research has mostly focused on short-term effects over hours or days. ${ }^{25}$ Earlier reports ${ }^{22} 2627$ also mentioned dosing regimens much higher than we have been using or seeing in clinical practice. ${ }^{2}$

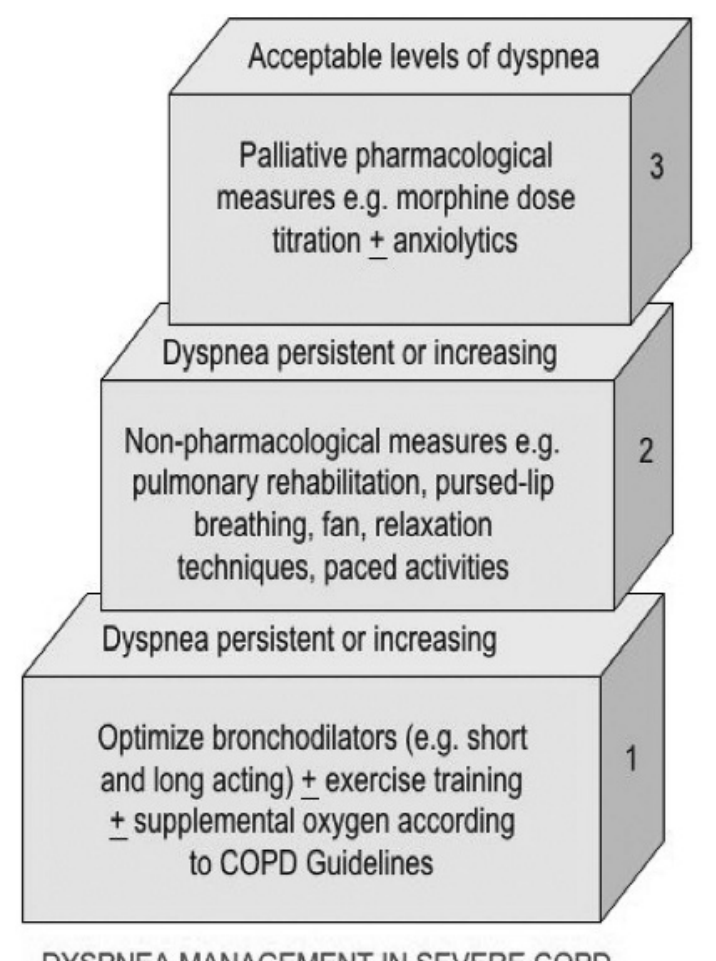

Figure 1 The dyspnoea ladder. Reproduced with permission from Rocker et al. ${ }^{2}$ 
The use of opioids for dyspnoea has been the subject of a Cochrane review in which 11/18 studies reported only patients with COPD (range 7-19 patients). This confirmed overall beneficial effects of both oral and parenteral opioids on dyspnoea $(p<0.001)$ and, from a meta-regression, that both were more effective than placebo, ${ }^{28}$ a conclusion supported by a subsequent report in 2004. ${ }^{29}$ By contrast, nebulised opioids did not appear to have any effect on dyspnoea. Nevertheless, we need to be clear that, of the 18 randomised controlled trials reviewed, ${ }^{28} 14$ involved single dosing of opioids. Four multiple dosing studies over a week or more involving patients with COPD used oral diamorphine, ${ }^{30}$ dihydrocodeine $e^{31}$ or morphine $^{22}$ (see table 1). Only one small study from New Zealand assessed quality of life ${ }^{22}$ and used a starting dose of sustained release morphine an order of magnitude higher than we are proposing. $^{22}$

Subsequent to the 2002 systematic review, ${ }^{28}$ Abernethy and colleagues published the results of a placebo controlled crossover trial of 48 patients (mostly with COPD) in which daily use of a sustained release morphine formulation had predominantly beneficial effects. ${ }^{25}$

In this 4-day crossover study, ${ }^{25}$ using $20 \mathrm{mg}$ sustained release morphine per $24 \mathrm{~h}$, the effects were positive, patients reporting improvements in their refractory dyspnoea and better sleep. The effect on dyspnoea was more evident later in the day (reflecting the use of a single $20 \mathrm{mg}$ dose slow release preparation and coinciding with peak serum levels late in the afternoon). Constipation was a problem for some patients. Ten of the original cohort of 48 had to withdraw from the study, only five for likely morphine-related side effects. ${ }^{25}$ Despite some adverse effects, this study was the first adequately powered randomised controlled trial that supported the use of an opioid for the symptomatic relief of dyspnoea. ${ }^{25}$ Secondary analyses of the study data failed to demonstrate a relation between severity of dyspnoea and subsequent response to opioids, ${ }^{33}$ and further dose-ranging trials or longer-term trials have yet to be reported but are in progress.

Opioids, when appropriately administered and monitored at lower doses, do not appear to cause significant respiratory depression. ${ }^{25}$ Several studies within the systematic review ${ }^{28}$ attest to the lack of adverse short-term effect on blood gases, also confirmed in a more recent study. ${ }^{34}$

\section{BARRIERS TO USE OF OPIOIDS IN ADVANCED COPD}

\section{Professional barriers}

Among professional societies there is a lack of consensus on the role of opioids in the treatment of dyspnoea in COPD. Documents from the European Respiratory Society and the American Thoracic Society make no recommendation, ${ }^{13}{ }^{35}$ and the National Institute for Health and Clinical Excellence in the UK states that: "Opiates can be used for the palliation of breathlessness in patients with end-stage COPD unresponsive to other medical therapy". "An earlier position paper from the American Thoracic Society specifically counselled against the use of opioids in COPD except in terminal stages. ${ }^{37}$ The Global Initiative for Chronic Obstructive Lung Disease (GOLD) makes a passing reference: "... some clinical studies suggest that

Table 1 Multiple dosing studies of opioids for dyspnoea among patients with COPD

\begin{tabular}{|c|c|c|c|c|c|}
\hline Study & Population & $\begin{array}{l}\text { Opioid dose } \\
\text { regimen (vs } \\
\text { placebo) }\end{array}$ & Setting & $\begin{array}{l}\text { Duration of } \\
\text { follow-up }\end{array}$ & Outcome measure \\
\hline $\begin{array}{l}\text { Eiser et al } \\
1991^{30}\end{array}$ & $\begin{array}{l}\mathrm{n}=18 \text { (pink } \\
\text { puffer, mean } \mathrm{FEV}_{1} \\
36 \% \text { ) }\end{array}$ & $\begin{array}{l}\text { Diamorphine } 2.5 \\
\text { or } 5 \mathrm{mg} \text { orally qid }\end{array}$ & $\begin{array}{l}\text { Pre and } 2 \text { week } \\
\text { exercise testing in } \\
\text { study centre }\end{array}$ & $\begin{array}{l}2 \text { weeks } \times 3 \text {, } \\
\text { crossover, no } \\
\text { washout }\end{array}$ & $\begin{array}{l}\text { VAS for dyspnoea } \\
6 \text { min walk }\end{array}$ \\
\hline $\begin{array}{l}\text { Poole et al } \\
1998^{22}\end{array}$ & $\begin{array}{l}\mathrm{n}=16\left(\mathrm{FEV}_{1}\right. \\
<1.5 \mathrm{I})\end{array}$ & $\begin{array}{l}\text { Morphine SR 10- } \\
20 \mathrm{mg} \text { od or bid }\end{array}$ & $\begin{array}{l}\text { Pre and } 6 \text { week } \\
\text { exercise testing in } \\
\text { study centre }\end{array}$ & $\begin{array}{l}6 \text { weeks } \times 2 \text {, plus } \\
2 \text { week washout }\end{array}$ & $\begin{array}{l}\text { CRO for quality of } \\
\text { life, } 6 \text { min walk }\end{array}$ \\
\hline
\end{tabular}

Overall effect on

dyspnoea Side effects

NS


morphine used to control dyspnoea may have serious adverse effects and its benefits may be limited to a few sensitive individuals". ${ }^{38}$ However, the absence of a single reported case of respiratory depression in the medical literature from low-dose regular oral opioids for dyspnoea raises questions about this assertion. Moreover, in a longitudinal study in Australia of 65 patients with refractory dyspnoea (predominantly due to COPD) where a slow release morphine preparation was prescribed in doses ranging from $10 \mathrm{mg}$ to $30 \mathrm{mg}$ daily, there were no cases of respiratory depression. In addition, $51 \%$ of patients reported benefit sufficient for them to remain on longterm opioids. ${ }^{34}$ Meanwhile, both the Australian and Canadian guidelines on COPD include qualified recommendations for considering opioids for severe dyspnoea, ${ }^{39}{ }^{40}$ as do the American College of Chest Physicians ${ }^{41}$ and the American Thoracic Society $^{42}$ in policy statements on palliative and end-of-life care.

For physicians, barriers to opioid use to relieve dyspnoea in COPD include discomfort and inexperience with potential side effects of sedation (uncommon if opioids are introduced at low regular doses and titrated carefully over days or weeks) and respiratory depression (not reported in the clinical literature where low-dose regular oral opioids are titrated to effect), lack of knowledge and experience regarding opioid prescription, pharmacokinetics, titration and appropriate monitoring of clinical response and side effects. Nevertheless, others have suggested that opioids should be considered, not only in end-oflife situations, but also for stable patients with COPD whenever breathlessness is severe and continues despite maximal bronchodilator therapy. ${ }^{23} 44$ The potential for use of opioids in this setting demands further study. Only quality evidence showing a clear benefit to risk ratio is likely to alter the prevailing mindset.

\section{Patient and family barriers}

Fears of using or of implications of using a narcotic or a controlled substance or having them in the house often underpins initial reluctance to consider opioids ${ }^{45}$ (and our collective feedback/personal experience), yet when this reluctance is overcome, the reduction of fear that morphine induces comes through as a consistent and positive theme. Case reports $^{2} 22434$ attest that, for some, the improvements in quality of life have been profound.

\section{OUR APPROACH TO USING OPIOIDS}

Opioid therapy is one of several potential approaches to the management of severe dyspnoea that includes both conventional pharmacological and non-pharmacological interventions that should be optimised first. Nevertheless, given that a high proportion of patients with advanced COPD experience severe dyspnoea on minimal exertion despite other conventional interventions, people struggling with dyspnoea related to COPD should not be denied an appropriately initiated and monitored trial of opioids, balancing benefits and any adverse effects as in any other clinical encounter. Of note, unlike almost all other medications in the pharmacocopoeia, opioids can be titrated effectively and safely over a wide range of doses to therapeutic effect.

A low-dose slow approach is important for several reasons, but gaining patients' and families' confidence is key. Gaining the confidence of the "opioid-naïve physician" unused to prescribing opioids in this situation is also important. Patients with COPD, in contrast to patients with cancer, have lived with breathlessness for years and may continue to live with it for prolonged periods. If confidence with opioids is lost through a "forced pace" regimen, patients will have lost an important and rare therapeutic intervention for dyspnoea. Interventions aim to minimise non-compliance due to opioid-related side effects and an acceptance that it may take time to see a therapeutic effect. However, it is important to anticipate and manage patient and caregiver expectations carefully with any cautious dose titration schedule so that they also do not look for an immediate and substantial effect. In advanced COPD, opioids should be titrated to achieve tolerable levels of dyspnoea according to the patients who take them. Unless contraindicated, in the UK and Canada, patients are usually started on oral immediate release morphine sulfate. The approach is slow initiation over the first week, with dose titration taking place at weekly intervals over 4 weeks. One recommended dose schedule suggests a start up dose of morphine sulfate of $1 \mathrm{mg}$ daily (can be $0.5 \mathrm{mg}$ twice daily) and, if tolerated, then $1.0 \mathrm{mg}$ twice daily in week 2 increasing by $1.0 \mathrm{mg}$ per week until the lowest effective dose is found to treat dyspnoea. ${ }^{46}$ In Canada we might start at a similar dose but move up to $1.0-2.5 \mathrm{mg}$ every $4 \mathrm{~h}$ by the end of week $1 .^{47}$ Patients are most likely to be dyspnoeic during waking hours when they are most active, so a dosing interval of 4-hourly while awake should ensure adequate levels of opioid during that time period while optimising the likelihood of compliance. If troublesome dyspnoea remains, a dose increase of $25 \%$ each week seems reasonable over 3-4 weeks. Once a stable dose is achieved (ie, there is no need for change over 2 week), colleagues in Canada will often substitute a twice daily sustained release preparation at a comparable daily dose. ${ }^{47}$ If patients experience persistent intolerable opioid-related side effects (possibly nausea or confusion), a reasonable clinical decision would be to consider other opioids (eg, rotation to an equipotent dose of oral hydromorphone using a conversion ratio of $1 \mathrm{mg}$ hydromorphone $=5 \mathrm{mg}$ morphine). Oxycodone may be used as an alternative opioid where there is geographical variation in the availability of hydromorphone although, to date, blinded studies have focused on morphine.

We provide patients and their caregivers and family practitioners with a simple guide to opioid titration and follow closely with telephone contact in the first weeks of therapy. There are tools available to monitor the presence and severity of common opioid-induced side effects that can be adapted from their use in the setting of pain relief in cancer. ${ }^{48}$ We provide advice concerning regular use of stool softener and stimulant laxative to prevent opioid-induced constipation.

\section{A RESEARCH AGENDA}

There are several questions to which we require answers from appropriately designed studies. Dose-finding studies and, ultimately, a sufficiently powered randomised controlled trial of longer term opioid therapy will provide definitive answers. However, randomised controlled trials of complex symptomatology common to palliative phases of illness are notoriously difficult to conduct and are not necessarily the gold standard in this setting. Other designs that incorporate qualitative elements designed to understand experiences from patient and caregiver perspectives would also seem appropriate. For the individual patient an $n=1$ study can be justified (for oral or nebulised opioids), and trial designs that include variations on the $n=1$ approach may well advance the field. These various approaches should help us to understand the following:

- What is the optimal initiation dose, dosing interval, titration schedule and delivery route?

- Does prescribing in COPD differ from patients with comparable severity of dyspnoea from other illnesses? 
- To what degree are beneficial effects or adverse effects of opioids sustained over time?

- Does the amplitude of any therapeutic effect correlate with severity of dyspnoea (ie, are opioids more likely to be of benefit in patients with severe dyspnoea at rest as opposed to those with dyspnoea limited to exertion, or are they more effective at relieving dyspnoea that is acute-for example, during an acute exacerbation-rather than chronic)?

- How does compliance with opioid therapy change over time and what are the factors that influence compliance (eg, side effects, patient or caregiver fears or misconceptions about addiction and dependence or fears about opioids hastening death)?

- Are some opioids more efficacious or tolerated better than others?

- Are patients with advanced COPD truly at a higher risk of opioid-induced complications than other patients with severe dyspnoea?

- Are conventional concerns with using appropriately dosed and monitored opioids in patients with mild degrees of hypercapnia justified?

Another important component of the research agenda will be to determine whether we can predict opioid responsiveness. The current evidence base suggests we cannot. ${ }^{33}$ However, it has been our experience that certain patients with COPD with dyspnoea respond more favourably to treatment with opioids than others, and those with lower levels of function may derive more benefit. ${ }^{33}$ The challenge is to distinguish those who are likely to benefit from treatment from those who are not, or from those who may even be harmed. The concept of variability in degree of opioid responsiveness in treating pain is widely recognised ${ }^{49}$ Factors that influence the variable response of pain to opioids may also apply to dyspnoea. In our experience, dyspnoea that is acute, unpredictable in onset, strongly associated with negative emotions (fear, anxiety, panic) and a sense of loss of control by reduction in activity is most likely to respond favourably to opioids. Dyspnoea that is chronic, predictable in onset, in which the degree of physical perception is greater than the negative affective components and which the patient feels able to control or abort by pacing or reducing activity is less likely to respond favourably. These concepts lend themselves to measurement and to the development of tools to further refine the potential for opioid responsiveness.

While we await answers that will only arise within the context of carefully performed clinical studies, can we justify denying patients with advanced COPD an approach to palliation of a symptom that is so often and so profoundly difficult to manage effectively within conventional pulmonary medicine practice?

\section{CONCLUSION}

As patients with advanced COPD approach the end of their disease trajectory, many suffer from unrelenting dyspnoea despite optimal conventional pharmacological and non-pharmacological therapies. We should not underestimate the profound psychosocial impacts that dyspnoea has on the quality of life of both patients and their families. Patients and families living with advancing COPD need an approach to care where we as clinicians understand contemporaneously both the chronic illness and palliative care needs of this population. To deny our patients carefully conducted trials of effective palliation while waiting for definitive proof of effect would be to turn our backs on one of the basic goals of medicine. If we ignore the needs for effective palliation for our patients with advanced COPD then, in the words of Professor Partridge in a recent Thorax editorial, ${ }^{50}$ we will "fail them from beginning to end".

Competing interests: None.

Provenance and peer review: Not commissioned; externally peer reviewed

\section{REFERENCES}

1. Murray CJ, Lopez AD. Mortality by cause for eight regions of the world: Global Burden of Disease Study. Lancet 1997;349:1269-76.

2. Rocker GM, Sinuff T, Horton R, et al. Advanced chronic obstructive pulmonary disease: innovative approaches to palliation. J Palliat Med 2007;10:783-97.

3. Abernethy AP, Wheeler JL. Total dyspnoea. Curr Opin Support Palliat Care 2008;2:110-3.

4. Goodridge D, Lawson J, Duggleby W, et al. Health care utilization of patients with chronic obstructive pulmonary disease and lung cancer in the last 12 months of life. Respir Med 2008;102:885-91.

5. Curtis JR. Palliative and end-of-life care for patients with severe COPD. Eur Respir J 2008; 32:796-803.

6. Spathis A, Booth S. End of life care in chronic obstructive pulmonary disease: in search of a good death. Int J Chron Obstruct Pulmon Dis 2008;3:11-29.

7. Mannino DM, Buist AS. Global burden of COPD: risk factors, prevalence, and future trends. Lancet 2007;370:765-73.

8. Gore JM, Brophy CJ, Greenstone MA. How well do we care for patients with end stage chronic obstructive pulmonary disease (COPD)? A comparison of palliative care and quality of life in COPD and lung cancer. Thorax 2000;55:1000-6.

9. Solano JP, Gomes B, Higginson IJ. A comparison of symptom prevalence in far advanced cancer, AIDS, heart disease, chronic obstructive pulmonary disease and renal disease. J Pain Symptom Manage 2006;31:58-69.

10. Elkington $\mathbf{H}$, White $\mathrm{P}$, Addington-Hall J, et al. The healthcare needs of chronic obstructive pulmonary disease patients in the last year of life. Palliat Med 2005;19:485-91.

11. Simpson AC, Rocker GM. Advanced chronic obstructive pulmonary disease: impact on informal caregivers. J Palliat Care 2008;24:49-54.

12. Rocker GM, Dodek PM, Heyland DK. Toward optimal end-of-life care for patients with advanced chronic obstructive pulmonary disease: insights from a multicentre study. Can Respir J 2008;15:249-54.

13. O'Donnell DE, Banzett RB, Carrieri-Kohlman V, et al. Pathophysiology of dyspnea in chronic obstructive pulmonary disease: a roundtable. Proc Am Thorac Soc 2007:4:145-68.

14. Evans KC, Banzett RB, Adams L, et al. BOLD fMRI identifies limbic, paralimbic, and cerebellar activation during air hunger. J Neurophysiol 2002;88:1500-11.

15. Lacasse $\mathbf{Y}$, Brosseau L, Milne $\mathrm{S}$, et al. Pulmonary rehabilitation for chronic obstructive pulmonary disease. Cochrane Database Syst Rev 2002;(3):CD003793.

16. Maltais F, Bourbeau J, Shapiro S, et al. Effects of home-based pulmonary rehabilitation in patients with chronic obstructive pulmonary disease: a randomized trial. Ann Intern Med 2008;149:869-78.

17. Eaton T, Garrett JE, Young $P$, et al. Ambulatory oxygen improves quality of life of COPD patients: a randomised controlled study. Eur Respir J 2002;20:306-12.

18. Currow DC, Abernethy AP. Pharmacological management of dyspnoea. Curr Opin Support Palliat Care 2007:1:96-101.

19. Booth S, Wade R, Johnson M, et al. The use of oxygen in the palliation of breathlessness. A report of the expert working group of the Scientific Committee of the Association of Palliative Medicine. Respir Med 2004;98:66-77.

20. Simpson AC, Rocker GM. Advanced chronic obstructive pulmonary disease rethinking models of care. OJM 2008;101:697-704.

21. Bausewein C, Booth S, Gysels M, et al. Non-pharmacological interventions for breathlessness in advanced stages of malignant and non-malignant diseases. Cochrane Database Syst Rev 2008;(2):CD005623.

22. Poole PJ, Veale AG, Black PN. The effect of sustained-release morphine on breathlessness and quality of life in severe chronic obstructive pulmonary disease. Am J Respir Crit Care Med 1998;157:1877-80.

23. Woodcock AA, Gross ER, Gellert A, et al. Effects of dihydrocodeine, alcohol, and caffeine on breathlessness and exercise tolerance in patients with chronic obstructive lung disease and normal blood gases. N Engl J Med 1981;305:1611-6.

24. Light RW, Muro JR, Sato RI, et al. Effects of oral morphine on breathlessness and exercise tolerance in patients with chronic obstructive pulmonary disease. Am Rev Respir Dis 1989;139:126-33.

25. Abernethy AP, Currow DC, Frith $\mathrm{P}$, et al. Randomised, double blind, placebo controlled crossover trial of sustained release morphine for the management of refractory dyspnoea. BMJ 2003;327:523-8.

26. Rice KL, Kronenberg RS, Hedemark LL, et al. Effects of chronic administration of codeine and promethazine on breathlessness and exercise tolerance in patients with chronic airflow obstruction. Br J Dis Chest 1987;81:287-92.

27. Runo JR, Ely EW. Treating dyspnea in a patient with advanced chronic obstructive pulmonary disease. West J Med 2001;175:197-201.

28. Jennings $\mathbf{A L}$, Davies AN, Higgins JP, et al. A systematic review of the use of opioids in the management of dyspnoea. Thorax 2002;57:939-44.

29. Foral PA, Malesker MA, Huerta G, et al. Nebulized opioids use in COPD. Chest 2004;125:691-4. 
30. Eiser N, Denman WT, West C, et al. Oral diamorphine: lack of effect on dyspnoea and exercise tolerance in the "pink puffer" syndrome. Eur Respir J 1991;4:926-31.

31. Woodcock AA, Johnson MA, Geddes DM. Breathlessness, alcohol, and opiates [letter]. N Engl J Med 1982:306:1363-4.

32. Johnson MA, Woodcock AA, Geddes DM. Dihydrocodeine for breathlessness in "pink puffers". BMJ (Clin Res Ed) 1983;286:675-7.

33. Currow DC, Plummer J, Frith $\mathrm{P}$, et al. Can we predict which patients with refractory dyspnea will respond to opioids? J Palliat Med 2007;10:1031-6.

34. Currow DC, Kenny B, McDonald C, et al. Multi-site open label dose ranging study to determine the minimum effective dose of sustained release morphine (SRM) for reducing refractory breathlessness. Eur J Palliat Care 2009 (in press).

35. Celli BR, MacNee W. Standards for the diagnosis and treatment of patients with COPD: a summary of the ATS/ERS position paper. Eur Respir J 2004;23:932-46.

36. Anon. Chronic obstructive pulmonary disease. National clinical guideline on management of chronic obstructive pulmonary disease in adults in primary and secondary care. Thorax 2004;59(Suppl 1).

37. American Thoracic Society. Dyspnea. Mechanisms, assessment, and management: a consensus statement. Am J Respir Crit Care Med 1999;159:321-40.

38. Rabe KF, Hurd S, Anzueto A, et al. Global strategy for the diagnosis, management, and prevention of chronic obstructive pulmonary disease: GOLD executive summary. Am J Respir Crit Care Med 2007:176:532-55.

39. Abramson MJ, Crockett AJ, Frith PA, et al. COPDX: an update of guidelines for the management of chronic obstructive pulmonary disease with a review of recent evidence. Med J Aust 2006;184:342-5.
40. O'Donnell DE, Aaron S, Bourbeau J, et al. State of the art compendium: Canadian Thoracic Society recommendations for the management of chronic obstructive pulmonary disease. Can Respir J 2004;11(Suppl B):7-59B.

41. Selecky PA, Eliasson CA, Hall Rl, et al. Palliative and end-of-life care for patients with cardiopulmonary diseases: American College of Chest Physicians position statement. Chest 2005;128:3599-610.

42. Lanken PN, Terry PB, Delisser HM, et al. An official American Thoracic Society clinical policy statement: palliative care for patients with respiratory diseases and critical illnesses. Am J Respir Crit Care Med 2008;177:912-27.

43. Markowitz AJ, Rabow M. Management of dyspnea in patients with far-advanced lung disease. JAMA 2002;287:2261.

44. Robin ED, Burke CM. Single-patient randomized clinical trial. Opiates for intractable dyspnea. Chest 1986;90:888-92.

45. Rocker GM, Young J, Horton R. Using opioids to treat dyspnea in advanced COPD: a survey of Canadian clinicians. 2008. www.chestnet.org (accessed 14 Aug 2009).

46. Booth S, Bausewein C, Higginson I, et al. Pharmacological treatment of refractory breathlessness. Expert Rev Respir Med 2009;3:21-36.

47. Dean MM. End-of-life care for COPD patients. Prim Care Respir J 2008;17:46-50.

48. Smith HS, Kirsh KL. Documentation and potential tools in long-term opioid therapy for pain. Med Clin North Am 2007;91:213-28.

49. Mercadante S, Portenoy RK. Opioid poorly-responsive cancer pain. Part 1: Clinical considerations. J Pain Symptom Manage 2001;21:144-50.

50. Partridge MR. Patients with COPD: do we fail them from beginning to end? Thorax 2003:58:373-5.

\section{Lung alert}

\section{Esomeprazole does not improve asthma control}

Current American asthma guidelines recommend assessing patients with poorly controlled asthma for gastro-oesophageal reflux disease (GORD) and treating silent GORD. However, these recommendations were based on studies on patients with GORD symptoms. This study is the first of its kind to evaluate whether the addition of proton pump inhibitors (PPIs) in silent GORD may improve the symptoms of asthma.

Four hundred and twelve patients with poorly controlled asthma receiving inhaled corticosteroids with no GORD symptoms or a history of GORD with minimal symptoms and not on antireflux medication were randomised to receive either $40 \mathrm{mg}$ esomeprazole twice daily or placebo for 24 weeks while continuing their asthma medications. Similar proportions of patients in each group had silent GORD. The primary outcome measure was the rate of episodes of poor asthma control. Secondary outcome measures included spirometry, bronchodilator response, nocturnal awakening, quality of life and asthma symptoms (assessed through questionnaires). Ambulatory $\mathrm{pH}$ monitoring was used to assess oesophageal reflux.

Forty percent of participants had silent GORD. Both primary and secondary outcome measures were similar between the two groups. No significant differences in asthma-related symptoms were found between patients with documented reflux and those without. Subgroup analyses did not identify any patients whose asthma symptoms benefited from PPIs.

It is concluded that silent GORD does not play a role in worsening asthma symptoms and may be more important in other diseases. The addition of esomeprazole to traditional asthma treatment therefore does not appear to be of benefit.

- The American Lung Association Asthma Clinical Research Centers. Efficacy of esomeprazole for treatment of poorly controlled asthma. N Engl J Med 2009;360:1487-99.

\section{J Alagaratnam}

Correspondence to: Dr J Alagaratnam, CT1 Core Medical Training, Royal Hampshire County Hospital, Winchester, Hampshire, UK; jas.alagaratnam@gmail.com 